\title{
PENGARUH KONDISI FISIK LINGKUNGAN KERJA DAN KEPEMIMPINAN TERHADAP ETOS KERJA PEGAWAI PADA BIRO HUBUNGAN MASYARAKAT KEMENTERIAN LINGKUNGAN HIDUP DAN KEHUTANAN JAKARTA
}

\author{
Siti Nazla Zakiyah ${ }^{1)}$; Sudarijati ${ }^{2}$ \\ Program Studi Managemen Fakultas Ekonomi Universitas Djuanda Bogor \\ Email : Siti,Nazla Zakiyah@unida.ac.id, atikmartono@gmail.com \\ Correpondence author : atikmartono@gmail.com
}

\begin{abstract}
The purpose of this research is to analyze the influence of physical conditon of the working environment and leadership to the work ethic of employees at Biro Humas. The respondents in this research consist of 43 employees who work at Biro Hubungan Masyarakat Kementerian Lingkungan Hidup and Kehutanan Jakarta. The result showed that all indicators expressed validity and reliability. The physical condition of the working environment $\left(X_{1}\right)$ and leadership $\left(X_{2}\right)$ effect the work ethic of employees at Biro Humas $(Y)$. Whereas, partially all the indicators give both positive and significant affect the work ethic of employees at Biro Hubungan Masyarakat.
\end{abstract}

Keywords: physical condition of working environment, leadership, work ethic.

\begin{abstract}
ABSTRAK
Tujuan dari penelitian ini adalah untuk menganalisis dampak kondisi fisik lingkungan kerja dan kepemimpinan terhadap etos kerja pegawai pada Biro Hubungan Masyarakat Kementerian Lingkungan Hidup dan Kehutanan Jakarta. Hasilnya diketahui bahwa semua indikator valid dan reliabel. Secara simultan, kondisi fisik lingkungan kerja dan kepemimpinan mempengaruhi etos kerja pegawai pada Biro Humas. Secara parsial, keduanya memiliki pengaruh yang positif dan signifikan terhadap etos kerja pegawai.
\end{abstract}

Kata Kunci: kondisi fisik lingkungan kerja, kepemimpinan, etos kerja

\section{PENDAHULUAN}

Sebuah instansi merupakan sekumpulan manusia yang saling bekerja dalam rangka mencapai tujuan bersana yang sudah ditetapkan sebelumnya. Dari penjelasan itu terlihat bahwa tercapainya tujuan organisasi tidak bisa dipisahkan dari aktivitas orang-orang yang menjadi anggotanya.

Berkaitan dengan pengelolaan organisasi dalam mencapai tujuannya, Hersey dan tasmara (2002) mengatakan bahwa etos kerja adalah suatu totalitas kepribadian dari individu serta cara individu mengekspresikan, memandang, meyakini, dan memberikan makna terhadap sesuatu yang mendorong individu untuk bertin-dak dan meraih hasil yang optimal. Apabila pada suatu instansi didapati pegawai dengan etos kerja yang rendah dalam melaksanakan pekerjaannya, maka instansi tersebut akan mengalami kerugian karena pegawai tidak bekerja berdasarkan kemampuan yang dimiliki. Sebaliknya, dengan etos kerja yang tinggi bisa membantu memaksimalkan produktivitas kerja pegawai dan memberikan kinerja yang optimal.

Suatu instansi, dalam melakukan kegiatannya, selain memperhatikan faktor-faktor internal juga wajib memperhatikan lingkungan kerja. Lingkungan yang ada sering disebut 
kondisi fisik lingkungan kerja. Kondisi kerja yang menyenangkan terlebih lagi kondisi dari pegawai dalam memulai pekerjaannya akan memperbaiki moral pegawai, perasaan senang dan kesungguhan kerja, peralatan yang baik, ruangan yang nyaman, keamanan.

Selain faktor lingkungan kerja, faktor kepemimpinan juga berpengaruh dalam memaksimalkan etos kerja. Untuk mencapai etos kerja yang maksimal, maka dibutuhkan kepemimpinan yang mampu mencerminkan pengaruh yang baik bagi pegawai. Bersamaan dengan tugas pimpinan yaitu mendorong kerjasama antara bawahan dan atasan dalam melaksanakan tugas pekerjaannya. Pemimpin dalam hubungan dengan karyawan merupakan hal yang penting, karena sikap pemimpin dalam menghadapi karyawan akan mempengaruhi sikap pegawai. Seorang pemimpin juga harus menerapkan iklim hubungan kerja yang menyenangkan diantara anggota organisasi.

Biro Humas adalah unsur penunjang tugas Kementerian Lingkungan Hidup dan Kehutanan di bidang hubungan masyarakat yang berada dibawah dan bertanggung jawab kepada Menteri LHK melalui Sekretaris Jendral. Dari hasil survey awal, diperoleh informasi tentang lingkungan kerja di Biro Humas kurang nyaman. Penyebabnya antara lain penerangan yang kurang baik dan ruangan yang kurang luas. Berdasarkan pengamatan awal, Biro Humas yang bertempat di Gedung Manggala Wanabakti yang memiliki bangunan 8 lantai dan Biro Hubungan Masyarakan di lantai 1, dan satu ruangan berada beberapa bagian kerja dan Biro Humas jumlah pegawai 43 orang, diantara kedua bagian tersebut tidak ada pemisah, sehingga karyawan kurang nyaman di dalam melaksankan tugasnya.

Sasaran kegiatan Biro Humas adalah meningkatkan citra positif Kementerian Kehutanan sebesar $10 \%$ pertahun, dengan pembanding citra positif tahun 2009 sebagai tahun dasar sebesar 55\%. Citra positif diukur dengan jumlah berita yang dimuat di media massa yang beritanya cenderung positif. Selain faktor kondisi fisik lingkungan kerja, faktor kepemimpinandi Biro Humasmasih belum optimal. Hal ini ditunjukan oleh kurang pahamnya pegawai dalam memahami perintah secara jelas, akibatnya berpengaruh pada etos kerja karyawan yang ada di Biro Humas Kementrian Lingkungan Hidup dan Kehutanan.

Kondisi fisik lingkungan kerja dan kepemimpinan merupakan faktor penting dalam perusahaan dalam memaksimalkan etos kerja pegawai, karena keduanya berhubungan langsung dengan manusia. Meskipun hubungan manusia di dalam instansi tersebut harmonis namun apabila tidak sebanding dengan tempat kerja sekitar kantor yang mendukung dan memadai maka tujuan perusahaan juga tidak akan berjalan maksimal. Jadi instansi harus mampu memberikan fasilitas yang nyamandan para pemimpin perusahaan memberikan teladan kepada karyawan agar menghargai sesama dan menciptakan keharmonisan guna mencapai kepuasan komunikasi yang bertujuan menciptakan etos kerja. Oleh sebab itu sangat penting untuk mengetahui pengaruh kondisi fisik lingkungan kerja dan kepemimpinan terhadap etos kerja pegawai pada Biro Humas Kementerian Lingkungan Hidup dan Kehutanan Jakarta.

\section{MATERI DAN METODE}

Etos kerja diartikan dengan jiwa atau watak seseorang dalam melaksanakan tugasnya yang dipancarkan keluar, sehingga memancarkan citra positif atau negatif kepada orang luar orang bersangkutan (Arief, 2003). Sementara itu, yang dimaksud dengan lingkungan kerja fisik adalah segala sesuatu yang ada di sekitar yang dapat mempengaruhi pegawai dalam menjalankan tugas-tugas yang dibebankan, misalnya penerangan, suhu udara, ruang gerak, keamanan, kebersihan, musik dan lain-lain (Nawawi, 2001). Di sisi lain, kepemimpinan dipahami sebagai cara pemimpin mempengaruhi perilaku bawahan, agar mau bekerja sama dan bekerja produktif guna meraih tujuan organisasi (Hasibuan, 2010).

\section{Pengaruh Kondisi Fisik Lingkungan Kerja (X) Terhadap Etos Kerja (Y)}

Menurut Supriadi dalam Subroto (2005), lingkungan kerja merupakan keadaan sekitar 
tempat kerja, baik secara fisik maupun non fisik, yang dapat memberikan kesan yang menyenangkan, mengamankan dan menentramkan

Kondisi fisik lingkungan merupakan hal terpenting didalam kelancaran dan kenyamanan bekerja. Kondisi fisik lingkungan kerja yang baik akan dapat meningkatkan produktifitas dan efisiensi kerja karyawan. Hal ini berkaitan dengan tempat dan kelengkapan material yang diperlukan dalam melaksanakan pekerjaannya. Menurut Manullang (2006) bahwa adanya lingkungan kerja fisik yang baik tidak saja dapat menambah produktifitas karyawan tetapi juga dapat meningkatkan efisiensi kerja. Kondisi fisik lingkungan kerja yang baik meliputi peralatan kerja yang memadai, ruang kerja yang nyaman, perlindungan terhadap bahaya, ventilasi yang baik, penerangan yang cukup dan bersih. Lingkungan kerja yang baik tidak saja dapat menambah kegairahan kerja, tetapi juga dapat meningkatkan efisiensi kerja.

\section{Pengaruh Kepemimpinan $\left(\mathbf{X}_{2}\right)$ Terhadap Etos $\operatorname{Kerja}(\mathbf{Y})$}

Menurut Hasibuan (2010), kepemimpinan adalah cara seorang pemimpin mempengaruhi perilaku bawahan agar mau bekerja sama dan bekerja secara produktif untuk mencapai tujuan organisasi. Seorang pemimpin betapapun hebat kepandaiannya, akan tetapi jika tidak jujur dan tidak bertanggung jawab, tidak disiplin atau tidak loyal, apalagi tak mampu bekerja sama, pasti merugikan organisasi. Tanpa etos kerja yang tinggi perusahaan tak mungkin meningkatkan produktivitas sebagaimana yang diharapkan. Menumbuhkan etos kerja kepada karyawan itu tidak mudah. Karena etos kerja tidak dapat dipaksakan. Harus tumbuh dari dua pihak, yakni atasan (pemimpin) dan bawahan (pegawai).

\section{Uji Asumsi Klasik}

Menurut Rasul dan Nurlelah (2010), asumsi klasik adalah beberapa asumsi yang mendasari validitas analisis regresi linier berganda. Asumsi klasik terdiri dari beberapa hal meliputi asumsi normalitas, tidak didapati adanya kendala multikolieritas dan autokorelasi, serta asumsi homoskedastisitas. Jika regresi linier berganda meme- nuhi semua asumsi di atas, maka dapat disimpulkan hasil estimasi regresi sudah baik.

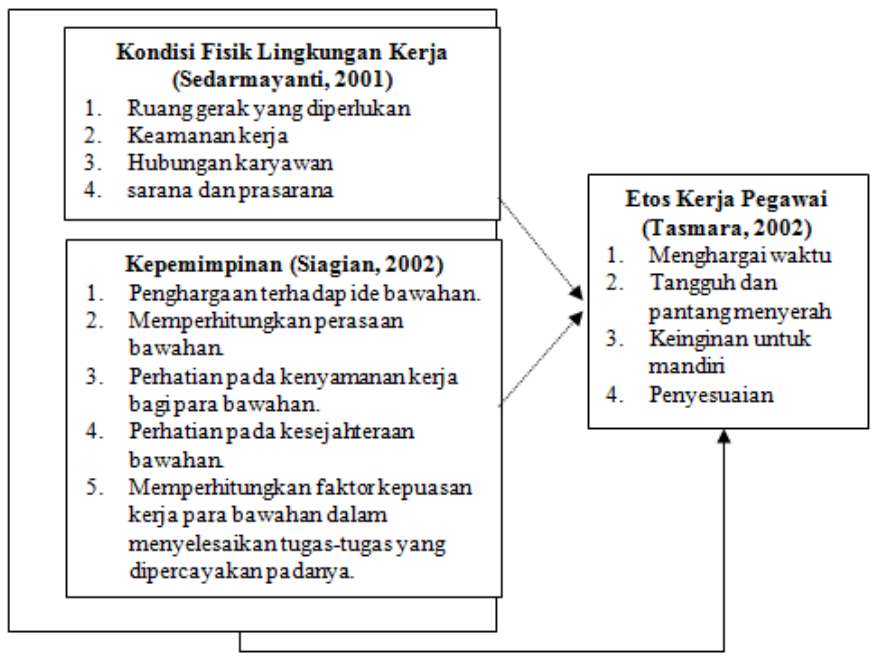

Gambar 1. Kerangka Konseptual Penelitian

Berdasarkan kerangka konseptual yang dibangun di atas, struktur hubungan variabel yang akan diuji dalam penelitian ini adalah sebagai berikut.

Gambar 2. Struktur Pengujian Variabel

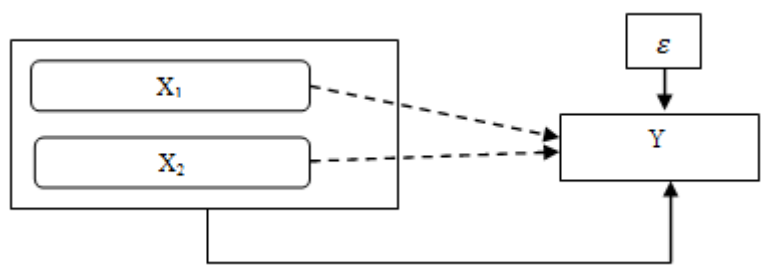

Studi ini menggunakan metode analisis berganda untuk mengidentifikasi besaran dampak (atau pengaruh) variabel bebas terhadap variabel terikat. Persamaan umum regresi berganda yaitu:

$$
Y=a+\beta_{1} X_{1}+\beta_{2} X_{2}+\varepsilon
$$

Berkaitan dengan estimasi model empiris di atas, studi ini mengemukakan dugaan sementara (hipotesis) yang adalah sebagai berikut:

1. Kondisi fisik lingkungan kerja memiliki pengaruh yang positif dan signifikan terhadap etos kerja pegawai

2. Kepemimpinan memiliki pengaruh yang positif dan signifikan terhadap etos kerja pegawai 


\section{HASIL DAN PEMBAHASAN}

Pada bagian awal hasil dan pembahasan, akan ditampilkan data deskriptif kuesioner dari masing-masing variabel penelitian, yang adalah sebagai berikut:
Berdasarkan tabel 2 diketahui jawaban responden untuk variabel kepemimpinan memiliki skor tertinggi 4,46 yakni untuk pandangan kemajuan perusahaan, kesetiaan, dan berpengetahuan luas. Sementara itu nilai rata-rata tanggapan karyawan yaitu sebesar 4,29.

Tabel 1. Rekapitulasi Tanggapan Pegawai Untuk Variabel $\mathrm{X}_{1}$

\begin{tabular}{llcc}
\hline No & \multicolumn{1}{c}{ Pertanyaan / Pernyataan } & $\begin{array}{c}\text { Penilaian } \\
\text { Pegawai }\end{array}$ & Interpretasi \\
\hline 1 & Kenyamanan lingkungan ruang kerja & 4,37 & Sangat nyaman \\
2 & Lingkungan tempat bekerja & 3,91 & Nyaman \\
3 & Hasil kerja yg didukung dengan ruang kerja. & 3,88 & Nyaman \\
4 & Kerapian tata ruang kerja & 4,07 & Nyaman \\
5 & Cahaya dalam ruang kerja . & 4,09 & Nyaman \\
6 & Penempatan peralatan. & 4,21 & Sangat nyaman \\
7 & Sirkulasi udara dalam bekerja. & 3,81 & Nyaman \\
\multicolumn{2}{c}{ Total } & 28,34 & \\
\hline Rata-rata penilaian pegawai terhadap kondisi fiisik lingkungan \\
kerja $\left(\mathrm{X}_{1}\right)$ & 4,05 & Nyaman \\
\hline
\end{tabular}

Berdasarkan tabel 1 rekapitulasi tanggapan pegawai untuk variabel $\mathrm{X}_{1}$, diketahui bahwa nilai tertinggi sebesar 4,37 ada pada pernyataan kenyamanan lingkungan ruang kerja. Secara keseluruhan, rata-rata tanggapan pegawai atas pernyataan dalam variabel $\mathrm{X}_{1}$ mencapai 4,05 . Dengan nilai rata-rata tanggapan sebesar ini, maka dapat dinyatakan secara deskriptif bahwa keseluruhan pegawai yang menjadi responden dalam penelitian ini merasa nyaman dengan kondisi fisik lingkungan kerja yang ada.
Dengan nilai rata-rata sebesar 4,29 untuk variabel $\mathrm{X}_{2}$ ini mengindikasikan bahwa secara deskriptif pegawai merasa pemimpinnya telah menampilkan gaya kepemimpinan yang sangat baik. Kepemimpinan yang dipersepsi sangat baik ini direspon secara positif oleh para pegawai. Penilaian pegawai paling tinggi untuk variabel kepemimpinan berada pada pernyataan pandangan kemajuan perusahaan (organisasi). Ini menunjukkan bahwa bagi responden, atasan memiliki arti penting terhadap sasaran dan tujuan perusahaan.

Tabel 2. Rekapitulasi Tanggapan Pegawai Untuk Variabel $\mathrm{X}_{2}$

\begin{tabular}{clcc}
\hline No & \multicolumn{1}{c}{ Pertanyaan / Pernyataan } & $\begin{array}{c}\text { Penilaian } \\
\text { Responden }\end{array}$ & Interpretasi \\
\hline 1 & Pandangan kemajuan perusahaan. & 4,46 & Sangat Baik \\
2 & Fokus pengembangan pemimpin & 4,37 & Sangat Baik \\
3 & Pemecahan masalah yan di lakukan pimpinan. & 4,37 & Sangat Baik \\
4 & Pemimpin mempunyai ambisi kuat dlm mencapai tujuan bersama. & 4,14 & Baik \\
5 & Perhatian pimpinan kepada bawahan. & 4,34 & Sangat Baik \\
6 & Pengawasan pimpinan terhadap bawahan. & 4,37 & Sangat Baik \\
7 & Ketrampilan komunikasi pimpinan. & 4,39 & Sangat Baik \\
8 & Pandangan pimpinan kemasa yang akan datang & 4,07 & Baik \\
9 & Kemampuan pimpinan mempengaruhi orang lain & 4,25 & Sangat Baik \\
10 & Kemampuan pimpinan mengarahkan tujuan karyawan & 4,32 & Sangat Baik \\
11 & Kemampuan pimpinanmenjadi simbol kelompok & 4,41 & Sangat Baik \\
12 & Kemampuan pimpinanmengarahkan pencapaian sasaran & 4,25 & Sangat Baik \\
13 & Kemampuan pimpinanmengarahkan sasaran kelompok & 4,05 & Baik \\
\hline \multicolumn{2}{r}{ Total } & 55,79 & \\
& Rata-rata penilaian pegawai terhadap kepemimpinan & 4,29 & Sangat Baik \\
\hline
\end{tabular}


Tabel 3. Rekapitulasi Tanggapan Pegawai Untuk Variabel Y

\begin{tabular}{clcc}
\hline No & \multicolumn{1}{c}{ Pertanyaan / Pernyataan } & $\begin{array}{c}\text { Penilaian } \\
\text { Responden }\end{array}$ & Interpretasi \\
\hline 1 & Pandangan kemajuan perusahaan. & 4,46 & Sangat Baik \\
2 & Fokus pengembangan pemimpin & 4,37 & Sangat Baik \\
3 & Pemecahan masalah yan di lakukan pimpinan. & 4,37 & Sangat Baik \\
4 & Pemimpin mempunyai ambisi kuat dlm mencapai tujuan bersama. & 4,14 & Baik \\
5 & Perhatian pimpinan kepada bawahan. & 4,34 & Sangat Baik \\
6 & Pengawasan pimpinan terhadap bawahan. & 4,37 & Sangat Baik \\
7 & Ketrampilan komunikasi pimpinan. & 4,39 & Sangat Baik \\
8 & Pandangan pimpinan kemasa yang akan datang & 4,07 & Baik \\
9 & Kemampuan pimpinan mempengaruhi orang lain & 4,25 & Sangat Baik \\
10 & Kemampuan pimpinan mengarahkan tujuan karyawan & 4,32 & Sangat Baik \\
11 & Kemampuan pimpinanmenjadi simbol kelompok & 4,41 & Sangat Baik \\
12 & Kemampuan pimpinanmengarahkan pencapaian sasaran & 4,25 & Sangat Baik \\
13 & Kemampuan pimpinanmengarahkan sasaran kelompok & 4,05 & Baik \\
\hline
\end{tabular}

Berdasarkan tabel rekapitulasi variabel etos kerja di atas, jawaban pegawai untuk variabel ini mempunyai skor tertinggi 4,34 yaitu kepedulian pegawai terhadap rekan kerja. Sementara itu nilai rata-rata tanggapan untuk variabel etos kerja adalah sebesar 4,15. hal ini menyiratkan bahwa sebagian besar pegawai menyatakan setuju atas pentingnya peranan etos kerja pegawai. Gambaran tersebut juga menunjukkan bahwa etos kerja secara umum adalah baik. Etos kerja tertinggi ditunjukkan dari segi kepeduliaan pada rekan kerja. Menurut Bender (2003), kepedulian akan menjadikan pegawai terlibat dengan orang lain. Kepedulian akan membuat seseorang mengutamakan kebutuhan dan perasaan orang lain daripada kepentingannya sendiri.

\section{Hasil Uji Asumsi Klasik}

Hasil pengujian asumsi klasik terhadap normalitas data, uji multikolinieritas, uji heteroskedastisitas menunjukkan bahwa data memenuhi seluruh persyaratan uji klasik.

\section{Hasil Estimasi Persamaan Regresi}

Bentuk persamaan diestimasi dengan metode regresi berganda. Adapun persamaan ini untuk menunjukan pengaruh variabel independen terhadap variabel dependen. Berdasarkan hasil penelitian, maka diperoleh suatu persamaan regresi dengan model taksiran adalah:

$$
Y=3,989+0,595 X_{1}+0,560 X_{2}+\varepsilon
$$

Berdasarkan informasi yang diperoleh dari tabel 4 diketahui bahwa variabel independen penelitian memiliki pengaruh positif dan signifikan terhadap variabel dependen. Dari persamaan regresi dapat disimpulkan jika kondisi fisik pada lingkungan kerja $\left(\mathrm{X}_{1}\right)$ dan kepemimpinan $\left(\mathrm{X}_{2}\right)$ berpengaruh positif terhadap etos kerja (Y). ini berarti bahwa semakin baik konidisi fisik lingkungan kerja dan kepemimpinan maka semakin tinggi etos kerja karyawan

Tabel 4. Hasil Estimasi Regresi

\begin{tabular}{|c|c|c|c|c|c|}
\hline \multirow[t]{2}{*}{ Model } & \multicolumn{2}{|c|}{$\begin{array}{l}\text { Unstandardized } \\
\text { Coefficients }\end{array}$} & \multirow{2}{*}{$\begin{array}{c}\text { Standardized } \\
\text { Coefficients } \\
\text { Beta } \\
\end{array}$} & \multirow[t]{2}{*}{$\mathrm{T}$} & \multirow[t]{2}{*}{ Sig. } \\
\hline & $B$ & Std. Error & & & \\
\hline (Constant) & 3,989 & 4,879 & & 0,818 &, 418 \\
\hline $1 \quad \mathrm{X} 1$ &, 595 & 277 & 294 & 2,147 & ,038 \\
\hline $\mathrm{x} 2$ &, 560 & ,132 &, 583 & 4,256 &, 000 \\
\hline
\end{tabular}

Secara keseluruhan, model empiris yang diestimasi dalam penelitian ini relatif baik. Sebagaimana diindikasikan dari nilai $R$ square model yang mencapai 69 persen, yang berarti bahwa variabel kondisi fisik lingkungan kerja dan kepemimpinan mampu menjelaskan 69 persen variasi dari variabel etos kerja pegawai. 
Sedangkan, sisanya sebesar 31 persen dijelaskan oleh variabel lain diluar model.

\section{KESIMPULAN DAN IMPLIKASI}

Berdasarkan tanggapan responden diketahui bahwa kondisi fisik lingkungan kerja secara keseluruhan adalah nyaman. Hal tersebut ditunjukkan dengan ruangan tempat kerja yang rapi, penerangan yang baik, sirkulasi udara yang cukup, dan kelembapan di ruangan yang cukup baik. Kepemimpinan di Biro Humas secara keseluruhan adalah sangat baik. Ditunjukkan dengan pemimpin memberi kesempatan kepada karyawan untuk memberi saran dalam menyelesaikan berbagai masalah yang ada di kantor, pemimpin selalu berinteraksi dengan bawahan dan pemimpin rutin mengontrol kerja bawahan. Etos kerja secara umum adalah tinggi. Etos kerja tertinggi ditunjukkan dari segi kepedulian kepada rekan kerja.

Sementara itu, berkaitan dengan pengujian hipotesis, penelitian ini mendapati bahwa baik kondisi fisik lingkungan kerja maupun kepemimpinan memiliki pengaruh yang positif dan signifikan terhadap etos kerja pegawai yang bertugas di Biro Hubungan Masyarakat Kementerian Lingkungan Hidup dan Kehutanan. Ini berarti bahwa semakin nyaman dan baik kondisi lingkungan kerja dan lingkungan kerja, maka akan semakin tinggi pula etos kerja pegawai.

Adapun saran yang diberikan sebagai berikut 1) Bagi Biro Humas diharapkan lebih meningkatkan kondisi fisik lingkungan kerja seperti ventilasi udara agar bisa tercipta tempat kerja yang kondusif sehingga bisa meningkatkan etos kerja karyawan. 2) Untuk kepemimpinan sendiri diharapkan dapat memberi contoh etos kerja misalnya menghargai waktu, tangguh dan pantang menyerah, keinginan untuk mandiri, penyesuaian diri terhadap karyawan bawahannya. 3) Untuk peneliti selanjutnya diharapkan agar dapat menambahkan beberapa variabel. Dengan tujuan dapat menambahkan pengaruh yang lebih luas lagi pada etos kerja. Adapun beberapa faktor lain yang mempengaruhi terbentuknya etos kerja karyawan, yaitu hubungan yang terjalin dengan baik antar karyawan (human relation), situasi, keamanan, dan keselamatan kerja yang baik bagi pegawai, keadaan sosial lingkungan kerja, perhatian pada kebutuhan rohani, jasmani maupun harga diri di lingkungan kerja, dan pemberian insentif yang menyenangkan bagi pegawai (Sinamo, 2005).

\section{DAFTAR PUSTAKA}

Anoraga, Pandji, 2001, Psikologi Kepemimpinan, Cetakan Ketiga, Rineka Cipta, Jaakarta.

Arifah, Nur, 2015,Pengaruh Human Relation (Hubungan Antar Manusia) dan Kondisi Lingkungan Fisik Terhadap Etos Kerja Karyawan Pada PT. Delta Merlin SandangTekstil 1 Sragen, Skripsi Sragen, Universitas Muhamadiyah Surakarta, Surakarta.

Arikunto, 2010, Prosedur Peneltian Suatu Pendekatan Praktik, Rineka Cipta, Jakarta.

Dessler, Garry, 2003,Human Resource Management Tenth Edition, Prentice Hall, New Jersey

Ega, Rukamana W, 2010, Analisis Pengaruh Human Relation dan Kondisi Fisik Lingkungan KerjaTerhadap Etos Kerja dan Kinerja Karyawan Dedy Jaya Plaza Tegal, Skripsi Semarang, Universitas Diponegoro Semarang, Semarang.

Flippo. Edwin B, 2002, Personel Management (Manajemen Personalia), Edisi VII jilis 1, Terjemahan Alponso S, Erlangga, Jakarta.

Ghozali, imam, 2011, Aplikasi Analisis Multivariate Dengan Program SPSS, Badan Penerbit Universitas Diponegoro. Semarang

Handoko T, Hani, 2000, Manajemen Personalia dan Sumber Daya Manusia, Edisi II, Cetakan Keempat Belas, Penerbit BPFE, Yogyakarta.

Hasibuan, Malayu SP, 2010, Manajemen Sumber Daya Manusia, Bumi Aksara Jakarta. 
Istijanto. 2005. Riset Sumber Daya Manusia (Cara praktis mendeteksi dimensidimensi kerja karyawan), PT.Gramedia Pustaka Utama. Jakarta.

Kartini, Kartono, 2001, Pemimpin dan Kepemimpinan, PT Raja Grafindo Persada, Jakarta.

Ma'arif, Syamsul dan Hendri Tanjung. 2003,Manajemen Opersional, Edisi Pertama, PT. Grasindo, Jakarta.

Manullang, Marihot AMH, 2005,Manajemen Personalia, Cetakan Ketiga. Gadjah Mada University Press, Yogyakarta.

Narimawati, Umi, 2010, Penulisan Karya Ilmiah, Penerbit Genesis, Jakarta.

Nazir, M. 2003,Metode Penelitian, Ghalia Indonesia, Jakarta.

Nurgiyantoro, Burhan. 2010,Teori Pengkajian Fiksi, Gajah Mada University Press, Yogyakarta.

Nurhadi, Subroto, 2005,Pengaruh Pelatihan, Motivasi dan Lingkungan Kerja Terhadap Kinerja Pegawai Dinas Peternakan dan Perikanan Kabupaten Semarang. Thesis Surakarta: Program Pascasarjana Magister Manajemen UMS, UniversitasMuhamadiyah Surakarta. Surakarta.

Ovi Setya Prabowo,2008, Analisis Pengaruh Human Relation, Kondisi Fisik Lingkungan Kerja dan Leadership terhadap Etos Kerja Karyawan Kantor Pendapatan Daerah Dipati, Skripsi Surakarta : Manajemen UMS.

Sedarmayanti, 2001,Sumber Daya Manusia dan Produktivitasnya, Mandar Maju. Bandung.
Simamora, Henry, 2009, Manajemen Sumber Daya Manusia, Edisi Ketiga. Cetakan Pertama, Penerbit Kencana. Jakarta

Sinamo, Jansen H, 2002, Etps Kerja 21 Etos Kerja Profesional di Era Digital Global, Ed 1, Mandar Maju. Bandung.

Sinamo, Jansen, 2011,8 Etos Kerja Profesiona, Institut Darma Mahardika. Jakarta.

Sondang, Siagianm, 2003, Manajemen Sumber Daya Manusia, Bumi Aksara, Jakarta.

Sugiyono, 2007,Statistika Untuk Penelitian,Penerbit Alfabeta, Bandung. 2012, Metode Penelitian Kuantitatif, Kualitatif dan $R \& D$,Alfabeta, Bandung. 2013, Metode Penelitian Kombina, Edisi Tiga, Alfabeta, Bandung.

Supardi. 2005,Metode Penelitian Ekonomi dan bisnis, UII Press, Yogyakarta.

Supramono, 2005, Desain Proposal Penelitian Studi Pemasaran, PT. Gramedia Pustaka Utama, Jakarta.

Tasmara, Toto, 2002,Membangun Etos Kerja Islam, Gema Insani Pers, Jakarta.

Terry, George R, 2005,Princples of Management, Alexander Hamilton Institute, New York.

Triantoro, Safaria 2004,Kepemimpinan, Edisi Pertama, Graha Ilmu, Yogyakarta.

Umar, Husein, 2003, Metedologi Penelitian Untuk Skripsi dan Tesis Bisnis, PT.Gramedia, Jakarta.

Yamit, Zulian, 2005, Manajemen Kualitas Produk dan Jasa, Ed 1, Ekonisia Kampus Fakultas Ekonomi UII Yogyakarta, Yogyakarta. 